\title{
“Green Economy “And Economic Security: Expectations And Reality
}

\author{
Temirbek S. Bobushev \\ Kyrgyz Economic University, Bishkek, \\ Kyrgyz Republic, 720033, Bishkek Togolok Moldo street 58,
}

\begin{abstract}
The development of a green economy and economic security are truly among the most discussed at the present time. However, the nature and degree of their discussions are sometimes so active and off scale that the causes or origins of these problems are forgotten. We are talking about global climate change and its, in most cases, negative impacts and manifestations on the economic condition and economic security of countries' development. The transition to a green economy system implies the expectation of a more stable and environmentally sustainable degree of development. At the same time, such a transition requires a deep restructuring, first of all, of the energy sector of the countries' economies. Despite the attractiveness of an environmentally friendly system of a green economy, today it is not possible for a complete and widespread transition to this economic system by most countries in the world. The problem is that, on the one hand, not all countries have the ability to replace fossil fuels in primary energy production with renewable sources due to their high cost, on the other hand, not all countries have "clean sources" of fuel and conditions for using alternative energy sources. Ultimately, there is a need to develop a long-term policy for a gradual and phased transition to a "green economy", which will make it possible to realistically determine the time frame for such transition.
\end{abstract}

Key words: green economy, economic security, fossil fuels, energy sources.

\section{Introduction}

The fact that global climate change is one of the most pressing and discussed problems of our time does not raise any particular doubts. The question is that in the course of the discussion we often observe unsuccessful "combinations" of various aspects of the above problem. Today, the discussion of the problem of global climate change is noted in various formats: environmental, economic, political, social, technical and technological. Therefore, it is no secret that recently there has been a tendency of more frequent use of the concept not "global warming", but "climate change". Turning to the problem of the development of the "green economy" and economic security, we note that here, too, examples of "mixing" of the causes and consequences of the manifestation of the observed changes of various levels and scales are quite often observed. In short, the concept of a green economy involves reducing emissions of used hydrocarbon products into the atmosphere and thereby reducing the volume of greenhouse gases that contribute to an increase in the air temperature of the surface layer of the atmosphere. Let me note right away that the increase in the content of carbon dioxide in the atmosphere can also be provided by the activity of volcanoes. By the way, the emissions from volcanoes in general can be practically comparable to the emissions from industrial enterprises in the world. Despite their obvious influence on the Earth's climate, scientists are not yet sure whether massive volcanic eruptions lead to an increase or decrease in temperatures, since no one has yet accurately estimated the volume of their emissions.

The active desire of some countries for an immediate transition to the use of alternative energy sources as the most important condition for the transition to a green economy is quite often restrained in reality. This is explained by the fact that, firstly, not all countries have the capabilities and appropriate natural conditions for the production of "clean" energy. Secondly, the use of alternative sources of energy production today is characterized by the high cost of such production. Even highly developed countries are forced to use 
"traditional" energy sources, just look at the structure of the energy sector of the countries (see below). This brings us to the first, albeit preliminary, conclusion on the issue under discussion. The solution to the problem of global climate change and its consequences naturally requires the use of different approaches and knowledge for decision-making. However, it should not be forgotten that an integrated approach to solving the above problem does not mean substituting economic or social examples for the facts of assessing environmental consequences. Moreover, the desire to make decisions as soon as possible on the noted problem, as well as other reasons, pushes the participants in the problem under discussion to discuss the environmental problem, most often in a political format and attempts to "impose" political decisions.

As you know, the discussion of the phenomenon of an increase in average temperature on the earth's surface dates back to the first half of the 19th century. In 1896 the Swedish scientist Svante Arrhenius [1] suggested that the accumulation of carbon dioxide in the atmosphere would increase the average temperature and calculated that if it doubled, the average temperature on the Earth's surface would rise by 5 degrees Celsius. In addition, Arrhenius hypothesized that a decrease in the concentration of carbon dioxide in the atmosphere is one of the causes of ice ages. Earlier, in 1827, the French physicist Jean-Baptiste Joseph Fourier [2] put forward the theory of the greenhouse effect, suggesting that water vapor, carbon dioxide, methane and ozone contained in the atmosphere capture and retain solar heat (for which they were named "greenhouse gases"). Another researcher, the Irish physicist John Tyndall, in 1859, using laboratory experiments, confirmed the existence of the greenhouse effect and put forward the idea that changing the concentration of gases in the atmosphere can also change the climate. Unfortunately, none of these theories were supported. Most scientists of that time were inclined to believe that climate change occurs very slowly and that humans are not able to influence it. The results of modern research, as of 2021, show that the measured concentrations of carbon dioxide in the atmosphere were almost 50\% higher than pre-industrial levels [3]. Despite the fact that natural sources of carbon dioxide are more than 20 times greater than those caused by human activities, natural sources gradually began to be balanced by natural sinks, mainly due to photosynthesis of carbon compounds by plants and sea waters. The absorption of terrestrial infrared radiation by long wavelength absorbing gases makes the Earth a less efficient emitter. Therefore, for the Earth to emit as much energy as it absorbs, the global temperature must rise, which is what is currently being observed.

\section{Materials and Methods}

The presence of carbon in the natural environment, as strange as it may sound, is a normal process. It is noted in materials of organic origin in sedimentary rocks, in silicate rocks and is associated with the activity of volcanoes on the Earth. At the same time, the rate of carbon emission is going on rather slow, which is a difficult research task. In general, it should be noted that it is not the state of the carbon content in the natural environment itself that is important, as an imbalance in the carbon cycle and subsequent changes in its level in the atmosphere. The fact is that a distinctive feature of the greenhouse properties of carbon dioxide in comparison with other gases is its long-term impact on the climate, which, even after the cessation of the emission that caused it, remains largely constant for up to a thousand years. Other greenhouse gases, such as methane and nitric oxide, do not remain free in the atmosphere for so long [4, 5]. The theory of global warming, unfortunately, cannot explain the fact that the content of carbon dioxide was once many times higher (especially before the appearance of oxygen), but life arose and flourished, the Venus scenario did not realize. This suggests negative feedback is present. Clouds reflecting solar radiation and appearing when the content of carbon dioxide is even higher than it is now can serve as such a "cooling" effect. Both phenomena - warming and cooling, thus are stabilizing mechanisms for the conditions of life on Earth [6]. However, despite the fact that the total anthropogenic emission of $\mathrm{CO}^{2}$ did not exceed $8 \%$ of its natural annual cycle (as of 2011), an increase in concentration was observed, due not only to the level of anthropogenic emissions, but also to a constant increase in the level of emissions over time (the so-called "accumulative effect").

To assess the anthropogenic component of greenhouse gases, as a result of emissions, it is necessary to proceed to the analysis of the structure of the use of sources of primary energy production. Such an analysis will be carried out on the basis of openly published sources of information, both in general within the OECD countries, and selectively for the countries with the largest carbon dioxide emissions. I note right away that the analysis of the situation with the development of greenhouse gases in the framework of mainly OECD countries and their proposed solutions for the control of carbon dioxide for countries around the world are at least not correct. There are a large number of developing and poor countries that are forced to use the 
resources they have for their daily needs. In this case, we are talking about the survival of the citizens of such countries and the improvement of the situation of the OECD countries. Therefore, the real implementation of the provisions of the Paris Agreement on climate presupposes not only a real reduction in air emissions, but also assistance to countries in need in solving their inherent problems.

\section{Results and Discussions}

When it comes to the problem of the growth of greenhouse gases and the corresponding negative impacts from climate change, it is first necessary to analyze and assess the main sources of emissions, primarily carbon dioxide, which pollutes the atmosphere. Despite the calculations of scientists, reflected in the report "Carbon Dioxide and Climate: A Scientific Assessment" [7], on the study of the consensus between advocates and opponents of the growth of carbon dioxide in the atmosphere and subsequent climate change, there are still groups of people who are spreading doubts among the public and successfully reducing the severity of such a threat. It should be noted, however, that a deeper scientific analysis of the state of fossil fuel use and other measures to reduce the amount of greenhouse gas in the atmosphere is required to take effective response measures. According to the proposals of politicians, public figures and informed citizens, the transition to a green economy should be ensured, first of all, by the transition to the use of sources of "clean energy or alternative energy sources. It is this point of view and such approaches that form the basis of state and public discussions at various levels at the present time. But how real is it and what is the actual policy for the production of primary energy?

Let us refer to the published materials on the use of fuel sources for the production of primary energy [8]. This 2000 World Energy Outlook presents expected changes in fossil fuel use through 2020. It also represents an important methodological advance as it proposes a new "reference scenario" that takes into account the specificities of greenhouse gas policies. Oil has been and remains the dominant fuel in the structure of primary energy production with a share of $40 \%$ [8]. This is because the transport sector continues to account for most of the growth in oil consumption, as well as the household, industrial and power generation sectors. The growth in demand for coal is mainly due to the generation of primary energy, so its share, despite efforts to reduce its share, amounted to almost $24 \%$ by 2020 . Coal retains its position as one of the world's largest sources of electricity. Despite the decline in the share of coal in OECD countries, it is increasing in developing countries, where coal production and its use in energy production are increasing. As you can see, from the information provided, the share of hydrocarbon fuels, which provides most of the $\mathrm{CO}^{2}$ emissions, is oil and coal. Despite the decline in the share of coal in OECD countries, it is increasing in developing countries, where coal production and its use in energy production are increasing. As you can see, from the information provided, the share of hydrocarbon fuels, which provides most of the $\mathrm{CO} 2$ emissions, is oil and coal. In the structure of primary energy production, they account for almost $65 \%$. Unlike oil and coal, natural gas is the fastest growing source of energy in the global energy mix, and its share in global primary energy demand is currently $26 \%$ (2020). While natural gas's environmental qualities are lower in carbon and other pollutants than oil and coal, it is also listed as a risk by those concerned about climate change. In general, the production of electricity from natural gas will increase more than three and a half times compared with the current level. At the same time, OECD countries accounted for almost half of the increase. Gas is likely to be the fuel of choice for power generation, as long as its price is relatively low and it can be regulated.

Thus, oil, coal and natural gas, traditional sources of primary energy production and the main air pollutants account for almost $87 \%$ of the total electricity production. Against the background of the above, the share of hydropower in the production of primary energy was only $3 \%$ in 2020, and the share of nuclear energy in the structure of primary energy production was about 5\% [8]. As you can see, despite the calls for the use of alternative sources in the production of primary energy - the sun, wind, underground hot waters, as well as tides, do not meet expectations, and their share is only a few percent. This is explained both by the high cost of their use and also by a certain "restraining" policy of the main energy consumers in the transport, industrial and energy sectors of the economy, especially in the developed countries of the world. As you can see, despite the calls for the use of alternative sources in the production of primary energy - the sun, wind, underground hot waters, as well as tides, do not meet expectations, and their share is only a few percent. This is explained both by the high cost of their use and also by a certain "restraining" policy of the main energy consumers in the transport, industrial and energy sectors of the economy, especially in the developed countries of the world. 
Let's move on to an analysis of the primary energy sources used in the countries that provide the largest carbon dioxide emissions into the atmosphere. For this purpose, let us refer to the indicators on the following countries (see Table 1). The information provided, although it is general in nature, still gives a fairly clear idea of the use of fossil fuels in the production of primary energy in the selected countries.

Table 1 . Sources of electricity production (in $\%$ of the total installed capacity) (compiled by the author based on materials [10]).

\begin{tabular}{|c|c|c|c|c|}
\hline Country & Fossil fuels & Nuclear fuels & $\begin{array}{c}\text { Hydroelectric } \\
\text { power plants }\end{array}$ & $\begin{array}{c}\text { Renewable } \\
\text { sources }\end{array}$ \\
\hline India & $71 \%(2016)$ & $2 \%(2017)$ & $12 \%(2017)$ & $16 \%(2017)$ \\
\hline USA & $70 \%(2016)$ & $9 \%(2017)$ & $7 \%(2017)$ & $14 \%(2017)$ \\
\hline Russia & $68 \%(2016)$ & $11 \%(2017)$ & $21 \%(2017)$ & $1 \%(2017)$ \\
\hline PRC & $62 \%(2016)$ & $2 \%(2017)$ & $18 \%(2017)$ & $18 \%(2017)$ \\
\hline EU & $44 \%(2015)$ & $12 \%(2015)$ & $11 \%(2015)$ & $44 \%(2015)$ \\
\hline
\end{tabular}

\section{Conclusions}

The necessary changes in countries' energy policies, technological developments and lower prices for fossil fuels over the medium and long term could have a major impact on energy demand and $\mathrm{CO}^{2}$ emissions. At the same time, electricity production should be motivated by the development and active use of alternative sources of energy production, which, ultimately, can contribute to the reduction of $\mathrm{CO}^{2}$ emissions. Ultimately, such proposals and actions should ensure a gradual and real transition to a green economy. However, to know what the system of "green economy" means does not mean at all what it is like to know when the calls of one group of people and countries, despite the general assurances of support for such a choice, are "restrained" by another group of politicians and countries lobbying their interests, even to the detriment of universal human aspirations and expectations. And these are no longer just expectations, but reality in addressing issues of global climate change management. The reality is that today the world is not yet ready for a complete transition to the production and use of clean energy. It is important not to deviate from the intended path, but to clearly build the concept of a phased transition to such a system. And most importantly, the transition to clean energy should be made by all countries of the world at approximately the same time, helping each other mutually. This conclusion is all the more important, since we all live on one planet, the ecological state of which should not depend on gigantic differences in thoughtless and poorly controlled consumption, in the broad sense of this word, as the main threat to the modern stage of human development. In this regard, the term "green economy" is more legitimate to change to "adaptive economy", which is more adequate to the state of use of this term not only in the theoretical, but also in the practical sense of this concept.

\section{References}

1. Arrhenius S. On the Influence of Carbon Acid in the Upon the Temperature of the Ground. // Philosophical Magazine and Journal Science (Fifth Series). — 1896. — Vol. 41. — P. 237-276.

2. Fourier, Joseph. Mémoire sur la température du globe terrestre et des espaces planétaires (fr.). Mémoires de l'Académie des sciences de l'Institut de France, 1827. — T. 7. — P. 569 - 604.

3. Fox, Alex. "The level of carbon dioxide in the atmosphere has reached a new high despite the reduction in pandemic emissions." Smithsonian Journal. Retrieved June 22, 2021.

4. Susan Solomon, et al. Irreversible climate change due to carbon dioxide emissions. Proceedings of the NAS, USA, 2008.

5. Judan, Cohen. Bundle Up, It's Global Warming. 2010.

6. Chen Zhou, Mark D. Zelinka and Stephen A. Klein. Influence of ten-year cloudiness changes on the Earth's energy budget. Nature Geosciences, 9, pp. 871-874, 2016.

7. Carbon Dioxide and Climate: A Scientific assessment. Report of an Ad Hoc Study Group on Carbon Dioxide and Climate, Woods Holl, Massachusetts, July 23-27, 1979. 
8. World Energy Outlook, 2000.

9. World Energy Outlook, 2021.

10. The World Factbook. November 4, 2021. 